\title{
Phytosterolaemia in three unrelated South African families
}

\author{
G.M.B. Berger, W.M. Deppe, A.D. Marais' ${ }^{1}$ and M. Biggs \\ Department of Chemical Pathology, University of Natal Medical School, Durban and 'Department of \\ Medicine, University of Cape Town Medical School, Cape Town, South Africa
}

Summary: Phytosterolaemia ( $\beta$-sitosterolaemia), a rare, autosomal recessive disorder, has not hitherto been reported in Southern Africa. We report four new homozygous patients, from three unrelated families with significant $\beta$-sitosterolaemia (6.6-11.3\%), campesterolaemia (2.2-4.6\%) and clearly detectable, though unquantified, levels of cholestanol. Three of the four patients had characteristic cutaneous and tendinous xanthomas within the first decade of life. The fourth patient, a 5 year old, was free of xanthomas despite persistently elevated concentrations of plant sterols in her plasma. All our patients were female bringing the male:female ratio in reported cases to 8:23. All were at or below the 50th percentile for height and weight, and presented at some stage with borderline, hypochromic anaemia associated with red cell abnormalities and thrombocytopaenia. The oldest patient showed suggestive clinical evidence of atherosclerosis affecting her aorta, ileofemoral bifurcation and possibly coronary arteries. All homozygotes responded to a diet restricted in phytosterols and the administration of cholestyramine with falls in plasma sterols of up to $68 \%$.

The recent discovery of a possible inherited defect in the synthesis of HMG CoA reductase in patients with phytosterolaemia makes this disorder a model system for studying the biological role of this enzyme in regulating the absorption and clearance of sterols other than cholesterol, and the factors governing the sterol composition of cell membranes.

\section{Introduction}

Phytosterolaemia ( $\beta$-sitosterolaemia) was first reported by Bhattacharyya and Connor in two sisters with extensive xanthomatosis and elevated levels of plant sterols in their plasma. ${ }^{1}$ Since that time a total of 27 patients have been described. ${ }^{2-16}$ The chief clinical features are tendon xanthomas as well as xanthomas in other sites, atherosclerosis, haematologic abnormalities and arthralgia. Hypercholesterolaemia is common and plant sterols, notably, $\beta$-sitosterol, constitute between $15 \%$ and $27 \%$ of the total plasma sterol content. The probable underlying metabolic abnormality is excessive intestinal absorption of plant sterols, which may be related to the defective 3 hydroxy-3 methyl glutaryl coenzyme A (HMG CoA) reductase synthesis recently reported by Salen and his associates. ${ }^{17,18}$ The clinical phenotype is inherited as an autosomal recessive disorder. ${ }^{19}$ We report a further four homozygous phytosterolaemic patients from three unrelated South African families, two white and

Correspondence: Professor G.M.B. Berger, B.Sc.(Med.), M.B., B.Ch., Ph.D., F.R.C.Path., Department of Chemical Pathology, Faculty of Medicine, University of Natal, PO Box 17039, Congella, 4013 South Africa.

Accepted: 14 April 1994 one Indian, and review briefly the possible pathogenesis of this disorder.

\section{Patients and methods}

\section{Proband I}

KIII2 (Figure 1), an Indian female, was referred at the age of 10 years with hypercholesterolaemia and a 1 year history of xanthomas. The family history was negative for premature coronary artery disease (CAD) or xanthomas. The patient had been healthy other than for the recent appearance of xanthomas and there were no features suggestive of secondary hyperlipidaemia. Physical examination revealed a small child with weight and height below the 3rd percentile for age (Table I), and with xanthomas present in both Achilles tendons, on her hands and over both elbows. A bruit was heard over the left carotid artery but her cardiovascular system was otherwise unremarkable. No splenic enlargement was noted. Plasma 'cholesterol' and low density lipoprotein 'cholesterol' (LDL-C) were both raised, her triglyceride level was normal but high density lipoprotein-'cholesterol' (HDL-C) 


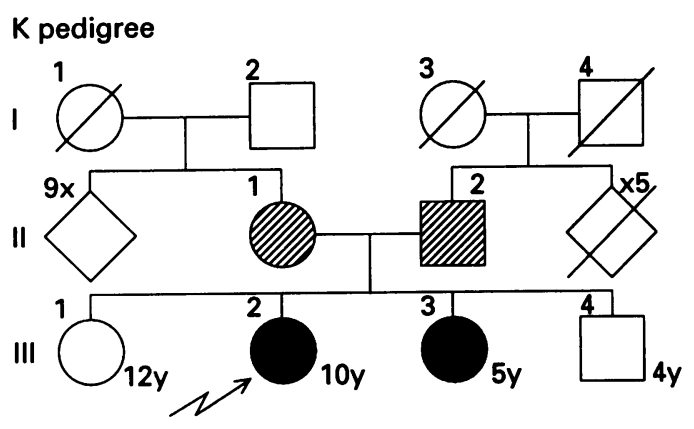

C pedigree

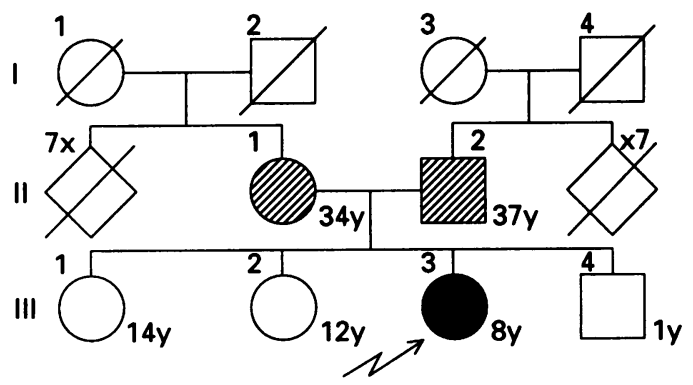

R pedigree
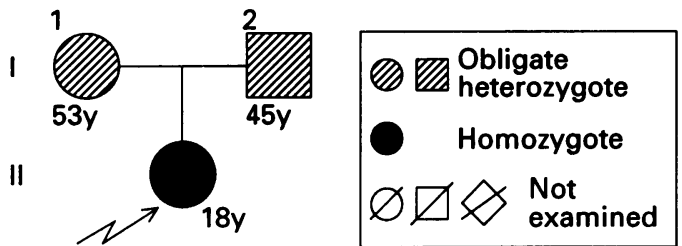

Figure 1 Pedigrees of phytosterolaemic families. was low (Table I). Renal and hepatic function was normal. Xanthomas were not detected in any of the proband's first-degree relatives.

A full blood count revealed the presence of hypochromia and microcytosis in the proband (KIII2) and her first-degree relatives, except for her brother (KIII4) who had slight lymphocytosis and neutropenia. The proband, her younger sister (KIII3) and her mother (KII1) were mildly iron deficient with reduced transferrin saturation (Table II) and were borderline anaemic. All the female members of this kindred showed a variety of red cell abnormalities besides the hypochromia and microcytosis, including polychromasia, the presence of schistocytes and elliptocytes (KIII1), and poikilocytes and anisocytes in the others. The proband's father and brother were neither iron deficient nor anaemic. Normal levels of haemoglobin $A_{2}$ and $F$ were found on haemoglobin electrophoresis in all family members. The females in the $\mathrm{K}$ kindred had large platelets and were all thrombocytopaenic on occasion except for KIII1.

\section{Proband 2}

CIII3 (Figure 1), an 8 year old white female, was referred with a history of xanthomatosis first noted at the age of 2 years. A 'cholesterol' determination performed just prior to referral was $8.24 \mathrm{mmol} / \mathrm{l}$ and her plasma triglyceride level was $2.38 \mathrm{mmol} / \mathrm{l}$. There was no history suggestive of a secondary hyperlipidaemia or myocardial ischaemia in the proband, but her maternal grandfather underwent a coronary artery bypass graft and her paternal grandfather suffered a myocardial infarct, while both were in their seventh decade. One paternal uncle had diabetes mellitus. On physical examination tendinous and tuberous xanthomas were found over the patient's knees, elbows and fingers and affecting both Achilles tendons. A xanthe-

Table I Clinical and laboratory features of phytosterolaemic homozygotes

\begin{tabular}{lcccccccccc}
\hline Patient* $^{*}$ & $\begin{array}{c}\text { Age } \\
(\text { years })\end{array}$ & $\begin{array}{c}\text { Weight } \\
(\mathrm{kg}) \dagger\end{array}$ & $\begin{array}{c}\text { Height } \\
(\mathrm{m}) \dagger\end{array}$ & $\mathrm{Tx}$ & $\mathrm{Cx}$ & $\mathrm{ATH}$ & $\begin{array}{c}\mathrm{CH} \\
(\mathrm{mmol} / \mathrm{l})\end{array}$ & $\begin{array}{c}\mathrm{TG} \\
(\mathrm{mmol} / \mathrm{l})\end{array}$ & $\begin{array}{c}H-C \\
(\mathrm{mmol} / \mathrm{l})\end{array}$ & $\begin{array}{c}L-\mathrm{C} \\
(\mathrm{mmol} / \mathrm{l})\end{array}$ \\
\hline KIII2 & 10 & $\begin{array}{c}22.0 \\
\left(<3^{\text {rd }}\right)\end{array}$ & $\begin{array}{c}1.25 \\
\left(<3^{\text {rd }}\right)\end{array}$ & $\mathrm{Y}$ & $\mathrm{Y}$ & $\mathrm{N}$ & 11.8 & 0.88 & 0.94 & 10.5 \\
KIII3 & 5 & $\begin{array}{c}19.0 \\
\left(<50^{\text {th }}\right)\end{array}$ & $\begin{array}{c}1.10 \\
\left(<40^{\text {th }}\right)\end{array}$ & $\mathrm{N}$ & $\mathrm{N}$ & $\mathrm{N}$ & 8.04 & 0.83 & 1.32 & 6.32 \\
CIII3 & 8 & $\begin{array}{c}19.0 \\
\left(\sim 10^{\text {th }}\right)\end{array}$ & $\begin{array}{c}1.19 \\
\left(<30^{\text {th }}\right)\end{array}$ & $\mathrm{Y}$ & $\mathrm{Y}$ & $\mathrm{N}$ & 5.04 & 0.81 & 1.20 & 3.47 \\
RII1 & 18 & $\begin{array}{c}44.0 \\
\left(<5^{\text {th }}\right)\end{array}$ & $\begin{array}{c}1.55 \\
\left(\sim 10^{\text {th }}\right)\end{array}$ & $\mathrm{Y}$ & $\mathrm{Y}$ & $\mathrm{Y}$ & 6.80 & 1.10 & 1.20 & 5.10
\end{tabular}

* See Figure 1; +figures in brackets refer to percentiles based on figures published by the National Centre for Health Statistics: Measuring Changes in Nutritional Status, World Health Organisation, Geneva, 1983. Tx = tendon xanthomas; $\mathbf{C x}=$ tuberous (cutaneous) xanthomas; $\mathbf{A T H}=$ arterial atherosclerosis; $\mathbf{C H}=$ enzymatic 'cholesterol'; TG = triglyceride; H-C = high density lipoprotein 'cholesterol'; L-C = low density lipoprotein 'cholesterol'; $\mathrm{Y}=$ yes; $\mathrm{N}=$ no. 
Table II Parameters of iron metabolism in $\mathrm{K}$ kindred

\begin{tabular}{lccccc}
\hline & $\begin{array}{c}\text { Haemoglobin } \\
(\mathrm{g} / \mathrm{l})\end{array}$ & $\begin{array}{c}P \text {-iron } \\
(\boldsymbol{\mu} \text { moll } / \mathrm{l})\end{array}$ & $\begin{array}{c}\text { Transferrin } \\
(\mathrm{g} / \mathrm{l})\end{array}$ & \% saturation & $\begin{array}{c}\text { Ferritin } \\
(\boldsymbol{\mu g} / \mathrm{l})\end{array}$ \\
\hline KII1 & 11.3 & 11.0 & 3.60 & 14.0 & 7.4 \\
KII2 & 13.3 & 20.7 & 3.54 & 26.1 & - \\
KIII1 & 9.1 & 3.4 & 4.32 & 3.5 & - \\
KIII2 & 11.1 & 10.9 & 3.45 & 14.0 & 45 \\
KIII3 & 10.8 & 7.7 & 3.69 & 9.3 & - \\
KIII4 & 11.9 & 15.1 & 3.35 & 20.1 & - \\
\hline
\end{tabular}

lasma was present on her left eyelid. No bruits or thrills were detected over her major arteries and all pulses were present. The remainder of her physical examination was non-contributory. Routine biochemical examination was normal but a full blood count showed the presence of microcytosis, hypochromia, a low normal haemoglobin level and large platelets in the absence of thrombocytopaenia. Biochemical studies revealed mild iron deficiency in the proband (iron $6.9 \mu \mathrm{mol} / 1$; transferrin $2.74 \mathrm{~g} / 1$; saturation $11 \%$; ferritin $18 \mathrm{mg} / \mathrm{l})$. The family members were all free of xanthomas, were haematologically normal and were not iron deficient.

\section{Proband 3}

RII1 (Figure 1), a 16 year old white female, presented with a history of arthralgia, xanthomatosis and raised lipids. At the age of 2 years, yellow conjunctival lesions were excised and thereafter 'lumps' on her elbows and knuckles were surgically removed at the ages of 8 years and 15 years. She had no history suggestive of secondary hyperlipidaemia or myocardial ischaemia other than pallor on exertion in the absence of chest pain. There was no family history of premature CAD or xanthomas. Examination revealed a small, thin girl (Table I) with bilateral Achilles tendon xanthomas and surgical scars over previous excision sites. A grade $2 / 6$ aortic stenosis was present without an ejection click and bruits were heard over the epigastrium and left ileofemoral region. Her blood pressure was $120 / 65 \mathrm{mmHg}$ and a resting electrocardiogram was normal. Total plasma 'cholesterol' was $6.6 \mathrm{mmol} / \mathrm{l}$ on initial examination and rose to $7.1 \mathrm{mmol} / 1$ on a subsequent visit. Further routine laboratory examination was normal. Both parents were hypercholesterolaemic but were free of xanthomas.

\section{Methods}

After an overnight fast, blood was collected from probands, family members and controls with minimal venestasis. EDTA plasma or serum was obtained after centrifugation of whole blood at approximately 3000 r.p.m. for 15-20 minutes within an hour of venepuncture. Assays were performed within 3 days with the samples kept at $4^{\circ} \mathrm{C}$ or on samples stored at $-70^{\circ} \mathrm{C}$ for periods of up to 3 months.

Our procedure for sterol extraction was modified from standard methods of lipid extraction. A total of $0.1 \mathrm{mg}$ internal standard ( $5 \alpha$-cholestane, Sigma Chemical Company, St Louis, MO, USA) was added to each $0.5 \mathrm{ml}$ serum or EDTA plasma. Saponification was carried out by incubating the sample with $5 \mathrm{ml} 0.5 \mathrm{~mol} / 1 \mathrm{KOH}$ in $90 \% \mathrm{v} / \mathrm{v}$ methanol overnight at room temperature followed by 105 minutes at $70^{\circ} \mathrm{C}$. The sterols were extracted into hexane, dried at $4^{\circ} \mathrm{C}$ under an air stream and reconstituted in $0.4 \mathrm{ml}$ methylene chloride. A $0.05 \mathrm{ml}$ aliquot of the methylene chloride extract was dried under vacuum and derivatized using BSTFA (Pierce Rockford, IL, USA) at $70^{\circ} \mathrm{C}$ for 1 hour. After drying under vacuum the derivatized sterols were reconstituted in $0.2 \mathrm{ml}$ chloroform.

Gas chromatography was carried out on a model 5890 Hewlett - Packard Gas Chromatograph using a $J$ and $W$ column (DB-1) with internal diameter $0.32 \mathrm{~mm}$ in the split mode (split ratio 10 ). The initial column temperature was $200^{\circ} \mathrm{C}$ increased to $260^{\circ} \mathrm{C}$ at $10^{\circ}$ /minute. After 10 minutes at $260^{\circ} \mathrm{C}$, two further ramps $\left(2^{\circ} / 10\right.$ minute to $\left.270^{\circ} \mathrm{C}\right)$ and $15^{\circ}$ /minute to $290^{\circ} \mathrm{C}$ ) were carried out. The volume injected was $0.5 \mu \mathrm{l}$, injection temperature $280^{\circ} \mathrm{C}$ ) and detector temperature $300^{\circ} \mathrm{C}$. Preliminary experiments on commercial standards of sitosterol, campesterol and stigmasterol (Sigma Chemical Company, St Louis, MO, USA) gave a linear response up to a ratio of $20: 1$ with the internal standard, representing plasma concentrations of approximately $10.4 \mathrm{mmol} / \mathrm{l}$. Recovery of unesterified sterols added to plasma $(n=5)$ was 98.4 (range 97-101\%). Total plasma cholesterol recovery by the GC procedure relative to the standard laboratory method using a commercial serum Biotrol-33 Plus (Biotrol ${ }^{\circledR}$ ) and plasma obtained from staff members was $97 \%$ (range $94-100 \%$ ), thus confirming complete hydrolysis. The coefficient of variation of the method was $2.5 \%$. 
Plasma 'cholesterol' was also assayed enzymatically using a commercial kit (Monotests, CHOD-PAP, High Performance Cholesterol assay, Boehringer Mannheim, Germany). HDL-C was determined on the supernatant after precipitation of VLDL and LDL-C by means of dextran sulphate-magnesium chloride. ${ }^{20}$ The sample volume was increased two-fold to permit adequate sensitivity. Triglycerides were measured enzymatically by means of the Periodochrome ${ }^{\circledR}$ Triglyceride GPO-PAP kit (Boehringer Mannheim, Germany) and LDL-C was calculated according to Friedewald's formula. ${ }^{21}$ The assays were standardized against frozen sera calibrated at the Centre for Disease Control (Atlanta, USA). The average analytical coefficient of variation in this laboratory is $3 \%$ for cholesterol, $4.8 \%$ for HDL-C and $2.7 \%$ for triglyceride. Routine biochemical and haematological assays were carried out using standard methods. The percentage iron saturation was calculated from the plasma iron concentration and transferrin levels, measured immunologically, taking into account the affinity constant for the divalent transferrin molecule.

\section{Results}

Quantitative sterol value on the probands and their family members obtained prior to treatment are summarized in Table III. The presumed homozygous status of the three probands was confirmed and an unsuspected fourth presumed homozygote, KIII3, the younger sister of the proband was identified in the $\mathrm{K}$ kindred. Her plant sterol content was $13.3 \%$ of total plasma sterols determined chromatographically and her cholestanol level was $0.17 \mathrm{mmol} / 1$ or $1.7 \%$ of total sterols. The plant sterols accounted for a significant proportion of the total sterol content in the homozygous subjects: sitosterol $6.6-11.3 \%$, campesterol $2.2-4.6 \%$ and stigmasterol $0.0-0.5 \%$. Cholestanol was present in small amounts on at least one occasion in all the homozygotes. Gas chromatographic (GC) cholesterol recovery was $96.7 \%$ of enzymatic 'cholesterol' in six control subjects but only $70-84 \%$ in the homozygous patients. Even when all the major sterol peaks including cholesterol were summed to yield a total GC sterol value, recoveries in the homozygotes ranged from $83 \%$ to $93 \%$ relative to enzymatically determined cholesterol.

Plant sterols in the parents (obligate heterozygotes) were generally unquantifiable by means of our 'standard' GC assay. Nevertheless, recovery of total GC sterol compared with enzymatic "cholesterol' was $\mathbf{9 3 . 9 \%}$, slightly lower than the control values and was suggestive of small amounts of plant sterol not seen as significant peaks on GC but included in the enzymatic assay. Heterozygosity in the remaining siblings cannot be excluded but GC-cholesterol was $99 \%$ of the enzymatic value (Table III). None of the six control subjects assayed showed quantifiable levels of plant sterols.

A diet restricted in plant sterols was instituted in all four homozygous subjects and cholestyramine (Questran ${ }^{\circledR}$ ) was additionally prescribed for the affected members of the $\mathrm{K}$ and $\mathrm{C}$ kindreds. The effect on both cholesterol and plant sterols was dramatic with reductions of up to $68 \%$ within $4-6$ months (Table IV) in the phytosterolaemic patients. Cholesterol and plant sterols showed a roughly equal fall in response to treatment. Regression of cutaneous xanthomas was noted in patients KIII2 and CIII3, even though the initial excellent biochemical response was not reproduced on each subsequent occasion.

\section{Discussion}

The presence of tendon xanthomata before the teens should alert the clinician to three disorders:

Table III Mean plasma sterol concentrations in phytosterolaemic kindreds and controls (ranges are given in parentheses)

\begin{tabular}{|c|c|c|c|c|c|c|}
\hline Subjects & $\begin{array}{l}E-C H O L \\
(\mathrm{mmol} / \mathrm{l})\end{array}$ & $\begin{array}{c}G C-C H O L \\
(\mathrm{mmol} / \mathrm{l})\end{array}$ & $\% R E C$ & $\begin{array}{c}\text { SITO } \\
(\% \text { TPS })\end{array}$ & $\begin{array}{c}C A M P \\
(\% \text { TPS })\end{array}$ & $\begin{array}{c}S T I G \\
(\% T P S)\end{array}$ \\
\hline $\begin{array}{l}\text { Homozygotes } \\
(n=4)\end{array}$ & $\begin{array}{c}8.83 \\
(7.53-11.80)\end{array}$ & $\begin{array}{c}6.55 \\
(5.81-8.36)\end{array}$ & 74 & 8.9 & 3.7 & 0.2 \\
\hline $\begin{array}{l}\text { Obligate heterozygotes* } \\
(n=6)\end{array}$ & $\begin{array}{c}6.52 \\
(4.87-8.63)\end{array}$ & $\begin{array}{c}6.12 \\
(4.43-8.09)\end{array}$ & 94 & NQ & NQ & NQ \\
\hline $\begin{array}{l}\text { Other first degree family } \\
(n=4)\end{array}$ & $\begin{array}{c}4.10 \\
(3.47-4.87)\end{array}$ & $\begin{array}{c}4.06 \\
(3.45-5.05)\end{array}$ & 99 & NQ & NQ & NQ \\
\hline $\begin{array}{l}\text { Controls } \\
(n=6)\end{array}$ & 4.92 & 4.76 & 97 & NQ & NQ & NQ \\
\hline
\end{tabular}

*Parents of probands. E-CHOL = enzymatic 'cholesterol'; GC-CHOL = gas chromatographic cholesterol; NQ = not quantified; SITO = B-sitosterol; CAMP = campesterol; STIG = stigmasterol; \%REC = recovery of GC-cholesterol relative to enzymatic cholesterol; \% TPS = percentage of total plasma sterol. 
Table IV Response of plasma sterols to diet and cholestyramine

\begin{tabular}{lcccc}
\hline & \multicolumn{2}{c}{$\begin{array}{c}\text { GC-cholesterol } \\
(\text { mmol/l) } \\
\text { Baseline }\end{array}$} & \multicolumn{2}{c}{$\begin{array}{c}\text { B-Sitosterol } \\
(\text { mmol/l) }\end{array}$} \\
KIII2 & 8.30 & $\begin{array}{c}2.81 \\
\text { Baseline }\end{array}$ & 1.13 & $\begin{array}{c}0.45 \\
\text { Minimum }\end{array}$ \\
KIII3 & 6.14 & $\begin{array}{c}-68 \%) \\
4.20\end{array}$ & 0.66 & $\begin{array}{c}-60 \%) \\
0.40 \\
(-32 \%)\end{array}$ \\
CIII3 & 5.81 & $\begin{array}{c}-3.65 \\
(-54 \%)\end{array}$ & 0.60 & $\left.\begin{array}{c}0.28 \\
(-53 \%) \\
0.34\end{array}\right)$ \\
RII1 & 6.16 & $\begin{array}{c}4.17 \\
(-32 \%)\end{array}$ & 0.45 & $\begin{array}{c}0.34 \%) \\
(-24 \%)\end{array}$ \\
\hline
\end{tabular}

homozygous familial hypercholesterolaemia (FHH), phytosterolaemia and cerebrotendinous xanthomatosis (CTX). All three of these conditions develop, in addition, cutaneous, tendinous and vascular sterol deposition, but only CTX is associated with cataract and central nervous system (CNS) infiltration. ${ }^{3}$ The plasma cholesterol is usually above $15 \mathrm{mmol} / 1$ in $\mathrm{FHH}$, but is normal in CTX and sometimes moderately increased in phytosterolaemia. Phytosterolaemia was diagnosed in our four patients on the basis of characteristic clinical features in three, and the presence of substantial quantities of sitosterol and campesterol in the plasma of all four subjects. Cholestanol and stigmasterol were much less elevated and were not always quantifiable by our assay method. Enzymatic 'cholesterol' was $15-30 \%$ higher than cholesterol measured by GC in the phytosterolaemic subjects. Plant sterols especially sitosterol, can generally be detected in the plasma of heterozygotes ${ }^{2,8}$ though failure to detect has also been reported. ${ }^{13}$ Contradictory results may reflect differing assay sensitivities, dietary intakes and possibly biological variation. Occasionally minor, unintegrated peaks were observed with mobilities corresponding to the phytosterols or cholestanol in probands or their family members. By increasing the injection volume quantification was theoretically achievable, but no systematic attempt was made in this study to determine the level of these minor components in obligate or potential heterozygote family members.

In phytosterolaemic subjects, the accumulation of plant sterols in circulating lipoproteins is accompanied by a more or less proportionate presence in xanthomas and in all tissues examined except brain. ${ }^{7}$ Haematologic abnormalities including anaemia accompanied by red blood cell abnormalities, increased osmotic fragility, haemolysis and hypersplenism have been recorded. ${ }^{4.89}$ Thrombocytopaenia and large platelets have also previously been noted, although none of these findings are present in all affected individuals. Three of the four homozygotes in this study showed haematological abnormalities including mild anaemia, hypochromia and microcytosis, other red cell dysmorphology, large platelets and some thrombocytopaenia. The fourth homozygote (RII1) had a history of mild anaemia and hypochromic red blood cells, but was haematologically normal in the course of the present study. Haematological and biochemical iron deficiency was present in both the $\mathrm{K}$ kindred and the $\mathrm{C}$ proband. Correction of the biochemical iron deficiency was apparently achieved in a number of the affected subjects with oral iron supplementation, but this had minimal effect on the haematological profile (data not shown). There was no evidence of $\beta$-thalassaemia on haemoglobin electrophoresis. Presumably some of the haematological defects are due to the abnormal sterol composition of the blood elements and hypersplenism as previously reported. An association between iron deficiency and phytosterolaemia has not previously been noted, but chance cannot be excluded since iron deficiency is not uncommon in this environment.

In vivo isotopic turnover studies have demonstrated markedly delayed clearance of both sitosterol and, more variably, cholesterol ${ }^{22-24}$ which, together with the enhanced absorption of phytosterols, results in the enormously expanded body pools (13-80-fold) of sitosterol observed in phytosterolaemic homozygotes. Absorption of phytosterols in heterozygotes is also slightly increased but body pools are normal in the absence of delayed clearance. ${ }^{2,3}$ Other in vivo experiments have also demonstrated diminished cholesterol synthesis. ${ }^{9,22,23}$ In vitro studies on mononuclear leucocytes $^{18,25}$ and on liver biopsies ${ }^{17}$ from sitosterolaemic subjects, showed reduced HMG CoA reductase immunoreactivity (enzyme mass) but normal catalytic activity ${ }^{2.18}$ expressed per unit mass of enzyme. The diminished enzyme mass correlated with reduced incorporation of label from $\left[{ }^{14} \mathrm{C}\right]$ acetate into cholesterol. ${ }^{25}$ The quantity of HMG CoA reductase specific mRNA was also markedly reduced in liver ${ }^{17}$ but showed normal mobility on agarose gel electrophoresis. A reduction in plasma sterols elicited by cholestyramine therapy caused a paradoxical decrease, rather than the expected increase, in HMG CoA reductase activity in two unrelated phytosterolaemic subjects, ${ }^{25}$ although LDL-receptor activity increased as expected.

These recent findings at the molecular level go some way in unravelling the complex functional disturbances in phytosterolaemic patients and suggest that defective synthesis of HMG CoA reductase is the primary defect in this disorder. Absorption of cholesterol from the gut is not receptor mediated but the failure of mucosal cholesterol synthesis may encourage partition of extracellular 
sterols, including phytosterols and shellfish sterols, ${ }^{26}$ into the mucosal cell membrane thus enhancing absorption. The increased LDLreceptor activity noted in phytosterolaemic subjects ${ }^{2}$ is likely to enhance plant sterol as well as cholesterol uptake from blood and intestinal fluid into cells. Together with the apparent breakdown in the normal membrane selectivity in favour of cholesterol, plant sterols replace cholesterol in tissues roughly in proportion to their concentration in the extracellular environment, thus accounting for the vastly expanded tissue pools. The presence of plant sterols in lipoproteins and in cells may contribute in various ways to the premature atherosclerosis and xanthomatosis characteristic of homozygous phytosterolaemia. ${ }^{23}$

The amount and nature of sterols incorporated into cell membranes can also significantly alter cell function. ${ }^{27,28}$ It may be pertinent to note that all four homozygotes in this study were female and of

\section{References}

1. Bhattacharyya, A.K. \& Connor, W.E. $\beta$-Sitosterolaemia and $x a n t h o m a t o s i s . A$ newly described lipid storage disease in two sisters. J Clin Invest 1974, 53: 1033-1043.

2. Salen, G., Shefer, S., Nguyen, L., Ness, G.C., Tint, G.S. \& Shore, V. Sitosterolaemia. J Lipid Res 1992, 33: 945-955.

3. Bjorkhem, I. \& Skrede, S. Familial diseases with storage of sterols other than cholesterol: cerebrotendinous xanthomatosis and phytosterolaemia. In: Scriver, C.R., Beadet, A.L., Sly, W.S. \& Valle, D. (eds) The Metabolic Basis of Inherited Disease. McGraw-Hill, New York. 1989, pp. 1283-1302.

4. Wang C., Lin, H.J., Chan, T.-K., Salen, G., Chan, W.-C. \& Tse, T.-F. A unique patient with coexisting cerebrotendinous xanthomatosis and $\beta$-sitosterolaemia. Am J Med 1981, 71: 313-319.

5. Khachadurian, A.K. \& Salen, G. Familial phytosterolaemia: cholestanolaemia and abnormal bile composition. Clin Res 1980, 28: 397A.

6. Whitington, G.L. \& Ragland, J.B. Neutral sterolaemia and xanthomas. Circulation 1979, 60: 33.

7. Salen, G., Horak, I., Rothkopf, M. et al. Lethal atherosclerosis associated with abnormal plasma and tissue sterol composition in sitosterolaemia with xanthomatosis. $J$ Lipid Res 1985, 26: 1126-1133.

8. Hidaka, H., Nakamura, T., Aoki, T. et al. Increased plasma plant sterol levels in heterozygotes with sitosterolaemia and xanthomatosis. J Lipid Res 1990, 31: 881-887.

9. Miettinen, T.A. Phytosterolaemia, xanthomatosis and premature atherosclerotic arterial disease: a case with high plant sterol absorption, impaired sterol elimination and low cholesterol synthesis. Eur J Clin Invest 1980, 10: 27-35.

10. Watts, G.F. \& Mitchell, W.D. Clinical and metabolic findings in a patient with phytosterolaemia. Ann Clin Biochem 1992, 29: 213-236.

11. Belamarich, P.F., Deckelbaum, R.J., Starc, T.J., Dobrin, B.E., Tint, G.S. \& Salen, G. Response to diet and cholestyramine in a patient with sitosterolaemia. Paediatrics 1990 , 86: 977-981.

12. Kwiterovich, P.O.Jr, Bachorik, P.S., Smith, H.H. et al. Hyperapobetalipoproteinaemia in two families with xanthoma and phytosterolaemia. Lancet 1981, ii: 466-469. the 27 patients we have been able to trace in the literature, 19 are female and eight are male. The ratio of male to female is thus $8: 23$ with the publication of these cases. The excess of female phytosterolaemic subjects may reflect a higher level of foetal deaths in male homozygotes or, less likely, lower viability to those HMG $\mathrm{CoA}$ reductase defective sperm carrying the $\mathrm{Y}$ chromosome. All our patients were small and lean possibly reflecting the systemic effects of this disorder.

\section{Acknowledgements}

This research was supported by grants from the South African Medical Research Council and the Atherosclerosis Risk Factor Research Programme to G.M.B. Berger. The Natal Provincial Administration is thanked for providing the facilities and the assistance of Mrs Noleen Henson in manuscript preparation is gratefully acknowledged.

13. Shulman, R.S., Bhattacharyya, A.K., Connor, W.E. \& Fredrickson, D.S. $\beta$-Sitosterolaemia and xanthomatosis. $N$ Engl J Med 1976, 294: 482-483.

14. Skrede, B., Bjorkhem, I., Bergesen, O., Kayden, H.J. \& Skrede, $\mathbf{S}$. The presence of $5 \alpha$-sitostanol in the serum of ao patient with phytosterolaemia and its biosynthesis from planto steroids in rats with bile fistula. Biochim Biophys Acta 1985, 836: 368-375.

15. Matsuo, I., Yoshino, K., Ozawa A \& Ohkido, M Phytosterolemia and type II hyperlipoproteinemia with tuberous xanthomas. J Am Acad Dermatol 1981, 4: 47-49.

16. McArthur, R.G., Roncari, A.K., Little, J.A., Kuksis, A., Myher, J.J. \& Marai, L. Phytosterolaemia and hypercholesterolaemia in childhood. J Pediatr 1986, 108: 254- 256.

17. Nguyen, L.B., Shefer, S., Salen, G., Ness, G.S., Ting, G.S. \& Zaki Ram, I. Molecular defect in cholesterol synthesis in sitosterolaemia with xanthomatosis. J Clin Invest 1990, 86: 926-931.

18. Nguyen, L.B., Salen, G, Shefer, S., Tint, G.S., Shore, V. \& Ness, G.C. Decreased cholesterol biosynthesis in sitosterolaemia with xanthomatosis: diminished mononuclear leucocyte 3-hydroxy-3-methyglutaryl coenzyme A reductase activity and enzyme protein associated with increased lowdensity lipoprotein receptor function. Metabolism 1990, 39: 436-443.

19. Beaty, T.H., Kwiterovich, P.O., Khoury, M.J. et al. Genetic analysis of plasma sitosterol, apoprotein B, and lipoproteins in a large Amish pedigree with sitosterolaemia. Am J Hum Genet 1986, 38: 492-504.

20. Lipid Research Clinics Programme. Manual of Laboratory Operations. Lipid and Lipoprotein Analysis Revised. US Department of Health and Human Services, Bethesda, MD, 1982.

21. Friedwald, W.T., Levy, R.I. \& Fredrickson, D.S. Estimation of the concentration of low-density lipoprotein cholesterol in plasma without the use of the preparative ultracentrifuge. Clin Chem 1972, 18: 499-502.

22. Lin, H.J., Wang, C., Salen, G., Lam, K. \& Chan, T. Sitosterol and cholesterol metabolism in a patient with co-existing phytosterolaemia and cholestanolaemia. Metabolism 1983, 32: $126-133$. 
23. Salen, G., Shore, V., Tint, G.S. et al. Increased sitosterol absorption, decreased removal, and expanded body pools compensate for reduced cholesterol synthesis in sitosterolaemia with xanthomatosis. $J$ Lipid Res 1989, 30: 1319-1330.

24. Bhattacharyya, A.K., Conner, W.E., Lin, D.S., McMurry, M.M. \& Shulman, R.S. Sluggish sitosterol turnover and hepatic failure to excrete sitosterol into the bile cause expansion of body pool of sitosterol in patients with sitosterolaemia and xanthomatosis. Arteriosclerosis Thromb 1991, 11: 1287- 1294.

25. Nguyen, L.B., Cobb, M., Shefer, S., Salen, G., Ness, G.C. \& Tint, G.S. Regulation of cholesterol biosynthesis in sitosterolaemia: effects of lovastatin, cholestyramine, and dietary sterol restriction. J Lipid Res 1991, 32: 1941-1947.
26. Gregg, R.E., Connor, W.E., Lin, D.S. \& Brewer, H.B.Jr. Abnormal metabolism of shellfish sterols in a patient with sitosterolaemia and xanthomatosis. J Clin Invest 1986, 77: 1864-1872.

27. Yeagle, P.L. Modulation of membrane function by cholesterol. Biochimie 1991, 73: 1303-1310.

28. Holmes, R.P., Mahfouz, M., Tavis, B.D., Yoss, N.L. \& Keenan, M.J. The effect of membrane lipid composition on the permeability of membranes to $\mathrm{Ca}^{2+}$. In: Biomembrane and Cell Function. Kummerow, F., Benga, G. \& Holmes, R.P. (eds) Annals of the New York Academy of Science, Vol. 414, 1983, pp. 44-56. 